Revista Brasileira de Agricultura Irrigada v.13, nº.5, p. 3619 - 3626, 2019

ISSN 1982-7679 (On-line)

Fortaleza, CE, INOVAGRI - http://www.inovagri.org.br

DOI: $10.7127 /$ rbai.v13n5001120

Protocolo 1120.19 - 25/03/2020 Aprovado em 30/03/2020

\title{
UTILIZAÇÃO DE BACTÉRIAS PROMOTORAS DE CRESCIMENTO EM MUDAS DE BANANEIRA SOB IRRIGAÇÃO SALINA
}

\author{
Ricardo Leoni Gonçalves Bastos ${ }^{1}$, Ana Janaina Oliveira Rodrigues ${ }^{2}$, Daniela Andreska da Silva ${ }^{3}$, \\ Cynthia Maria Rodrigues Nogueira ${ }^{4}$, Alan Bernard Oliveira de Sousa ${ }^{5}$
}

\section{RESUMO}

Objetivou-se avaliar o efeito da aplicação de bactérias promotoras de crescimento na produção de mudas de bananeira sob irrigação salina. $\mathrm{O}$ experimento foi conduzido na Embrapa Agroindústria Tropical, localizada no município de Fortaleza, Ceará. Os tratamentos foram dispostos em blocos ao acaso (DBC) em esquema fatorial $3 \times 4$, referentes aos três tratamentos utilizados (controle, bactéria e adubo) e aos quatro níveis de salinidade da água de irrigação $\left(0,5 ; 1,5 ; 3,0\right.$ e 4,5 dS m m $\left.^{-1}\right)$ com 4 repetições. Após 60 dias de experimento foram mensuradas as variáveis comprimento radicular (CR), altura da planta (AP), diâmetro do pseudocaule (DP), número de folhas (NF), área foliar (AF), massa fresca e seca das folhas (MFPA e MSPA, respectivamente) e teor de água nas folhas (TAF). As bactérias não apresentaram influência nas respostas das mudas de bananeira ao estresse salino.

Palavras-Chave: musa spp., estresse salino, bacillus sp.

\section{USE OF BACTERIAS PROMOTERS OF GROWTH IN BANANA SEEDLINGS UNDER SALINE IRRIGATION}

\begin{abstract}
The objective of this study was to evaluate the effect of the application of bacterias promoters of growth on the production of banana seedlings under saline irrigation. The experiment was conducted at Embrapa Agroindústria Tropical, located in the municipality of Fortaleza, Ceará.The treatments were arranged in randomized blocks (DBC) in a $3 \times 4$ factorial scheme, referring to three treatments used (control, bacteria and fertilizer) and the four levels of irrigation water salinity $(0,5,1,5,3,0,4,5$

\footnotetext{
${ }^{1}$ Discente em Agronomia, Universidade Federal do Ceará, Fortaleza, Ceará, Brasil. leoni.acad@gmail.com

2 Mestranda em Engenharia Agrícola, Universidade Federal do Ceará, Fortaleza, Ceará, Brasil. Janainarodrigues22@hotmail.com

${ }^{3}$ Discente em Agronomia, Universidade Federal do Ceará, Fortaleza, Ceará, Brasil. daniela.andsk@ gmail.com

${ }^{4}$ Discente em Engenharia de Pesca, Universidade Federal do Ceará, Fortaleza, Ceará, Brasil. mariiacynthia@ gmail.com

5 Prof. do Departamento de Engenharia Agrícola, Universidade Federal do Ceará, Fortaleza, Ceará, Brasil. alan.sousa@ufc.br
} 
$\mathrm{dS} \mathrm{m}^{-1}$ ) with 4 replicates. After 60 days of experiment, measured the variables root length (CR), plant height (AP), pseudocaule diameter (DP), number of leaves (NF), leaf area (AF), fresh and dry shoot mass (MFPA and MSPA, respectively) and leaf water content (TAF). The bacteria had no influence on the responses of banana plantlets to saline stress.

Keywords: musa spp., saline stress, bacillus sp.

\section{INTRODUÇÃO}

A bananicultura apresenta grande importância no cenário internacional como um dos principais ramos do agronegócio, sendo a segunda fruta fresca mais produzida no Brasil, com 6.764.324 toneladas, atrás apenas da laranja (CARVALHO et al., 2017). A banana (Musa sp.) é uma fruta cultivada na maioria das regiões tropicais e subtropicais, movimentando a economia e gerando emprego e renda de forma direta e indireta, além de representar importante fonte de renda para os agricultores menos capitalizados (COSTA et al., 2016; SALOMÃO et al., 2016). Segundo o Faostat (2019), o Brasil é o quarto maior produtor mundial com 6,67 milhões de toneladas, atrás apenas da Índia, China e Filipinas.

No Brasil, a bananeira é uma das espécies frutíferas mais cultivadas em todas as regiões do país, onde as diversas condições de clima (temperatura, umidade relativa, precipitação e insolação) favorecem que a produção seja distribuída durante todo o ano (EPAGRI, 2013). No Nordeste brasileiro, as fruteiras ocupam lugar de destaque na economia regional, respondendo com $35,79 \%$ da produção nacional (IBGE, 2018), com cultivos cada vez mais ligados à agricultura irrigada. Entretanto, essa região é em grande parte semiárida, caracterizada por uma média anual de precipitação abaixo de $800 \mathrm{~mm}$ e índice de aridez de 0,5 com risco de seca maior que $60 \%$ (PEREIRA JÚNIOR, 2007), se destacando em relação as demais regiões pela escassez hídrica que associada a altas taxas evapotranspiratórias resulta no aumento da demanda por água pelas plantas.

A baixa disponibilidade hídrica dessa região, torna necessário o uso alternativo de fontes de água para agricultura, como a utilização de águas salinas.
A salinidade atua como um dos fatores abióticos que afetam o desenvolvimento da bananeira, está inibe o crescimento e a produtividade na maioria das culturas, cuja resposta é atribuída ao desbalanceamento nas relações hídricas e nutricionais das plantas e ao acúmulo de íons considerados tóxicos (LACERDA et al., 2011; PRAZERES et al., 2015).

Assim, o uso de água de baixa qualidade para a irrigação pode ser um fator limitante para a produção vegetal, em função dos efeitos osmóticos e tóxicos (MUNNS, 2008). Portanto, considera-se importante estudos que avaliem as limitações das culturas ocasionadas pelas condições que interferem na produção vegetal tal como as limitações ocasionadas pela qualidade da água de irrigação.

A utilização de microorganismos encontrados naturalmente no solo podem melhorar a resposta vegetal a doenças e aos estresses abióticos; e em alguns casos otimizar o uso da água na agricultura. Evidenciando assim sua importância econômica, social e ambiental. Estudos recentes indicam a importância dos microrganismos endofíticos na agricultura, como a potencialidade da diminuição do uso de fertilizantes e defensivos químicos. Assim, diminuindo os custos de produção, promovendo a bioestimulação, além da sustentabilidade ambiental (FERNANDES et al., 2009).

Dessa forma, a utilização de microrganismos existentes naturalmente no solo pode servir como alternativa para promover o desenvolvimento vegetal e proporcionar um incremento na tolerância aos estresses abióticos. Portanto, o objetivo desse trabalho é avaliar o efeito da aplicação de bactérias promotoras de crescimento na produção de mudas de bananeira sob irrigação salina. 


\section{MATERIAL E MÉTODOS}

O experimento foi conduzido em ambiente protegido na Embrapa Agroindústria Tropical, no município de Fortaleza, Ceará, coordenadas geográficas $03^{\circ} 75^{\prime} \mathrm{S}, 38^{\circ} 57^{\prime} \mathrm{W}$, altitude média $37 \mathrm{~m}$.

O clima da região, segundo a classificação de Köppen, é do tipo Aw', tropical chuvoso, com temperaturas elevadas e com estação chuvosa predominante no outono. A temperatura média mensal durante a condução do experimento foi de $27,4{ }^{\circ} \mathrm{C}$, a umidade relativa foi de $70 \%$ e a precipitação de $14,4 \mathrm{~mm}$.

Foram utilizadas mudas micropropagadas de bananeira cv Prata Catarina. As mudas foram dispostas em espaçamento triangular em bandejas de polietileno, contendo substrato comercial esterilizado. Após 45 dias, as mudas foram transplantadas para sacos de polietileno contendo $1,4 \mathrm{~kg}$ de substrato na proporção $3: 1$ (3 solo autoclavado: 1 substrato comercial autoclavado).

O delineamento estatístico foi o de blocos ao acaso (DBC) em esquema fatorial 3 $\mathrm{x} 4$, referente aos três tratamentos (água controle; adubo de liberação lenta Osmocote ${ }^{\circledR}$ 14-14-14 (5,0 $\left.\mathrm{kg} \mathrm{m}^{-3}\right)$; bactérias promotoras de crescimento - Bacillus sp.) e aos quatro níveis de salinidade da água de irrigação $(\mathrm{S} 1=0,5 ; \mathrm{S} 2=1,5 ; \mathrm{S} 3=3,0$ e $\mathrm{S} 4=4,5$

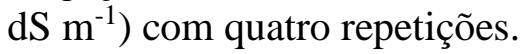

Para obtenção das concentrações salinas na água de irrigação, foram adicionados os sais de $\mathrm{NaCl}, \mathrm{CaCl} 2, \mathrm{MgCl}$ na proporção de (7:2:1), utilizando a água com condutividade elétrica média de $0,5 \mathrm{dS} \mathrm{m}^{-1}$. A aplicação de água salina foi iniciada três dias após o transplantio (DAT). O manejo da irrigação foi realizado em função do peso das mudas pelo método de lisímetro de pesagem. As mudas (saco de $\mathrm{PE}+$ substrato + planta) eram irrigadas sempre que atingiam peso menor ou igual a $80 \%$ da capacidade máxima de armazenamento, de modo que com a irrigação retornassem a capacidade máxima de $100 \%$.

Ao término do experimento, foram mensuradas as seguintes variáveis: altura da planta (AP) e comprimento radicular (CR) com o uso de uma régua milimetrada, diâmetro do pseudocaule (DP) usando paquímetro digital, número de folhas $(\mathrm{NF})$, área foliar (AF) utilizando medidor de superfície (LI - 3100, Área Meter, Li-Cor., Inc., Linln, 87 Nebraska, USA), massa fresca e seca das folhas (MFPA e MSPA, respectivamente), teor de água nas folhas (TAF) e eficiência do uso da água (EUA).

Os resultados obtidos no experimento foram submetidos à análise de variância pelo software estatístico SAEG (SAEG, 2007), no qual os tratamentos foram comparados pelo teste $\mathrm{F}$, e as médias dos tratamentos pelo teste de Tukey com 5\% de significância. A análise dos níveis de salinidade, foram submetidas a análise de regressão.

\section{RESULTADOS E DISCUSSÃO}

O resumo das análises de variância para os dados morfológicos de altura de planta (AP), comprimento de raiz (CR), diâmetro do caule (DP), número de folhas (NF), área foliar (AF), massa fresca e seca da parte aérea (MFPA e MSPA respectivamente) e teor de água na folha (TAF) de bananeiras cv. Prata Catarina pode ser observado na Tabela 1. Houve influência significativa em nível de $1 \%$ de probabilidade pelo teste $\mathrm{F}$ na fonte de variação níveis de salinidade (S) sobre todas as variáveis, exceto comprimento radicular $(\mathrm{p}>0,05)$ e altura da planta $(\mathrm{p}<0,05)$. Os tratamentos (T) apresentaram significância para diâmetro do pseudocaule, massa seca da parte aérea e teor de água na folha ao nível de $1 \%$ e para as variáveis número de folhas a nível de $5 \%$ probabilidade. Houve interação entre as fontes de variação (S) x (T) para a variável teor de água na folha a nível de $5 \%$. 
Tabela 1. Resumo da análise de variância para os dados de comprimento radicular (CR), altura das plantas (AP), diâmetro do pseudocaule (DP), número de folhas (NF), área foliar (AF), massa fresca e seca da parte área (MFPA e MSPA respectivamente) e teor de água na folha (TAF) de plantas de bananeira cv. Prata Catarina submetidas a diferentes tratamentos e níveis de salinidade.

\begin{tabular}{|c|c|c|c|c|c|c|c|c|c|}
\hline F.V & G.L & $\mathrm{CR}$ & $\mathrm{AP}$ & DP & $\mathrm{NF}$ & $\mathrm{AF}$ & MFPA & MSPA & TAF \\
\hline Blocos & 3 & $184,43^{\mathrm{ns}}$ & $1,43^{\mathrm{ns}}$ & $3,04^{\mathrm{ns}}$ & $0,97^{\mathrm{ns}}$ & $10753,72^{\mathrm{ns}}$ & $3,49^{\mathrm{ns}}$ & $0,22^{\mathrm{ns}}$ & $13,85^{\mathrm{ns}}$ \\
\hline Salinidade (S) & 3 & $56,33^{\mathrm{ns}}$ & $10,24 *$ & $39,69 * *$ & $17,14 * *$ & $138293,7 * *$ & $204,51 * *$ & $3,64 * *$ & $33,40 * *$ \\
\hline Tratamento $(\mathrm{T})$ & 2 & $228,34^{\mathrm{ns}}$ & $3,80^{\mathrm{ns}}$ & $44,80 * *$ & $3,81 *$ & $65991,63^{\mathrm{ns}}$ & $74,79^{\mathrm{ns}}$ & $4,08 * *$ & $85,89 * *$ \\
\hline Int. S x T & 6 & $9,60^{\mathrm{ns}}$ & $2,58^{\mathrm{ns}}$ & $6,16^{\mathrm{ns}}$ & $0,28^{\mathrm{ns}}$ & $12196,71^{\mathrm{ns}}$ & $19,59^{\mathrm{ns}}$ & $0,51^{\mathrm{ns}}$ & $22,18^{*}$ \\
\hline Resíduo & 33 & 138,66 & 3,39 & 4,34 & 0,84 & 25002,68 & 29,30 & 0,40 & 6,79 \\
\hline $\mathrm{CV}$ & $(\%)$ & 44,30 & 16,41 & 16,01 & 18,75 & 42,20 & 42,78 & 47,59 & 2,88 \\
\hline
\end{tabular}

$\mathrm{FV}=$ fonte de variação; $\mathrm{GL}=$ graus de liberdade; $\mathrm{CV}=$ coeficientes de variação; ${ }^{\text {ns }}$ - Não significativo, ${ }^{* *}$ - Significativo a $1 \%$ de probabilidade pelo teste $\mathrm{Fe}{ }^{*}$ - Significativo a $5 \%$ de probabilidade pelo teste $\mathrm{F}$.

A salinidade da água de irrigação afetou negativamente a altura das plantas (AP), diâmetro do pseudocaule (DP), número de folhas (NF), área foliar (AF) e matéria seca da parte aérea das bananeiras (MSPA) (Figuras 1A, 1B, 2A, 2B e 3A, respectivamente), com decréscimos relativos comparados ao tratamento sem salinidade, com valores de, $3,68,6,47,10,74,11,66$ e $16,35 \%$ para cada incremento unitário de CEa.

Resultado similares para altura de planta foram encontrados por Araújo Filho et al. (1995), que estudando a salinidade em cultivares de bananeira, observaram uma redução de 17 a $28 \%$ na altura das plantas em comparação com bananeiras cultivadas em solo não salino. Reduções na AP também foram obtidos por Neves et al. (2002) e Gomes et al. (2005), o que ressalta a sensibilidade da bananeira a níveis crescentes de salinidade.

Para a variável diâmetro do pseudocaule, foi obtido no experimento um decréscimo de $6,47 \%$ em relação ao tratamento sem salinidade, resultados estes similares ao de Carmo (2003) que verificou reduções na altura, número de folhas, área foliar e diâmetro do pseudocaule das bananeiras Pacovan e Marmelo quando submetidas a níveis crescentes de salinidade da água de irrigação. Silva et al. (2009) avaliando salinidade também em bananeira obteve reduções de $35,07 \%$ no diâmetro médio do pseudocaule.
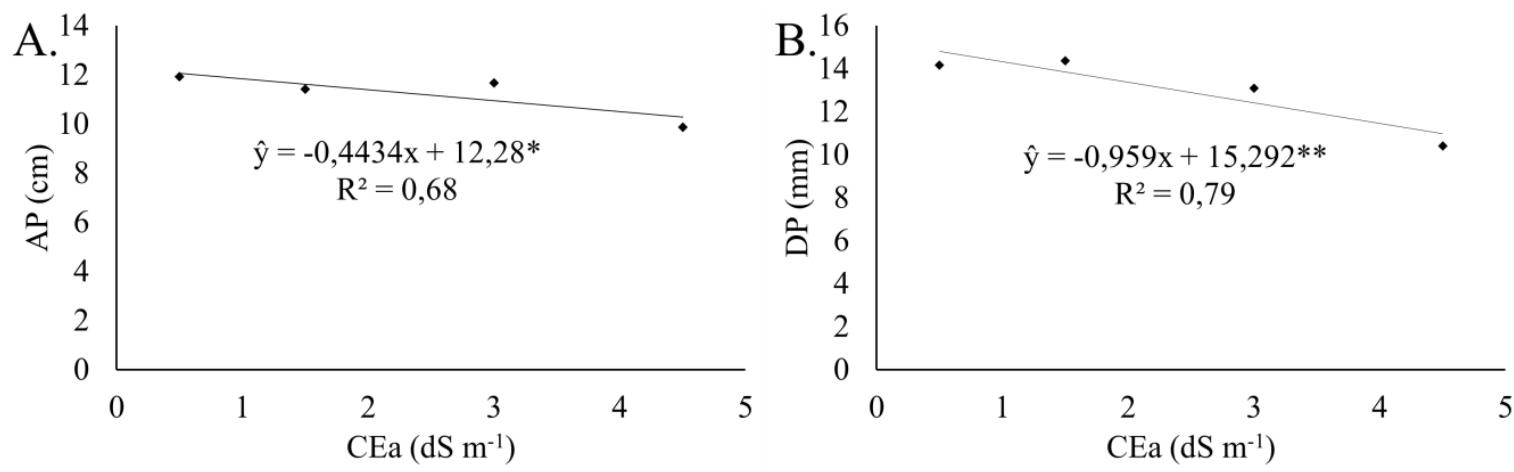

Figura 1. (A) Altura da planta; (B) diâmetro do pseudocaule de plantas de bananeira cv Prata Catarina, irrigadas com águas de diferentes concentrações salinas (CEa de 0,5, 1,5, 3,0, 4,5 dS m ${ }^{-1}$ ). 

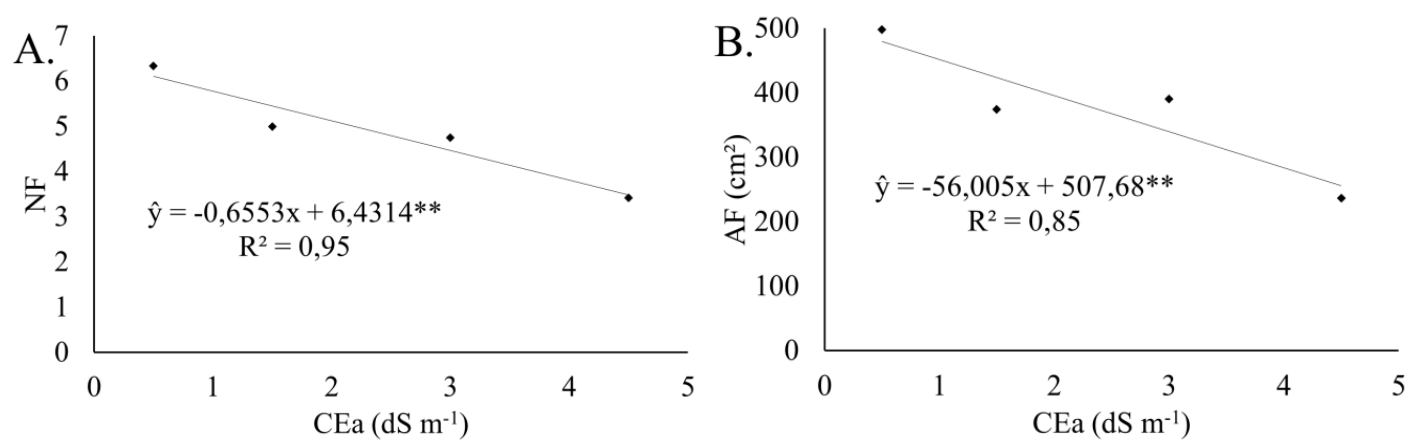

Figura 2. (A) Número de folhas; (B) área foliar de plantas de bananeira cv Prata Catarina, irrigadas com águas de diferentes concentrações salinas (CEa de 0,5, 1,5, 3,0, 4,5 dS m ${ }^{-1}$ ).
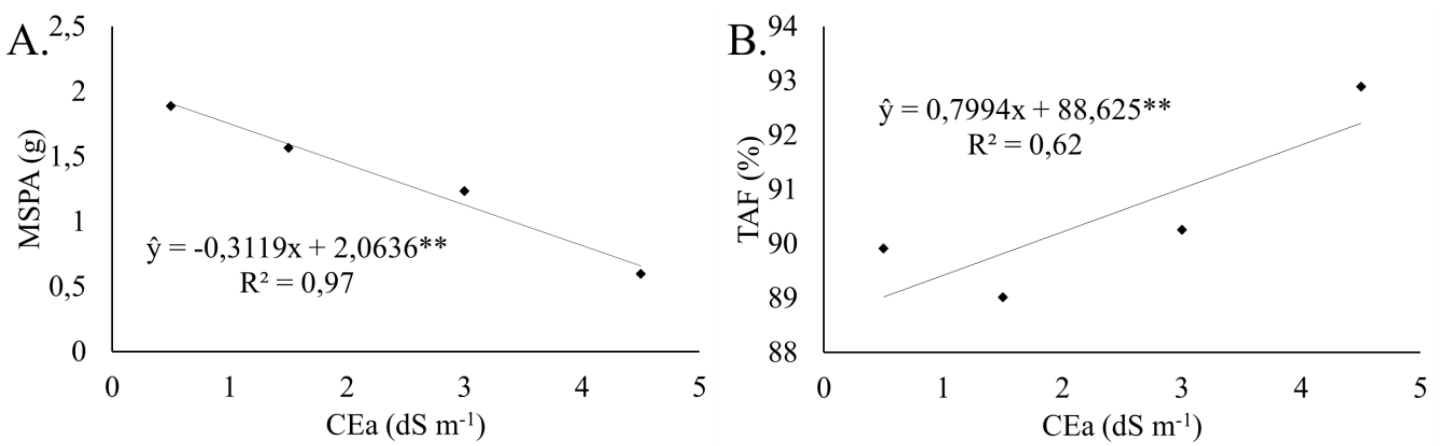

Figura 3. (A) Massa seca da parte aérea; (B) teor de água na folha de plantas de bananeira cv Prata Catarina, irrigadas com águas de diferentes concentrações salinas (CEa de 0,5, 1,5, 3,0, 4,5 dS m²).

Avaliando a produção de mudas de mamoeiro, Sá et al. (2013), verificou o decréscimo no número de folhas com o aumento da salinidade da água de irrigação, o que induziu à queda da área foliar. $\mathrm{O}$ mesmo resultado foi obtido por Sousa et al. (2015) trabalhando com mini melancia cv. Smile e Oliveira et al. (2010) trabalhando com girassol.

A diminuição da área foliar em função do estresse ocasionado pela salinidade está relacionada à dificuldade da planta em absorver água do solo (estresse osmótico). Consequentemente, a diminuição da área foliar ocasiona redução da área para transpiração da planta (MUNNS; TESTER, 2008).

Akbari et al. (2015) estudando o efeito da salinidade na cultura do milho, observaram um efeito negativo da salinidade nas variáveis massa seca e altura de plantas. A salinidade também afetou a área foliar e massa seca das folhas de berinjela (LIMA et al., 2015), bem como o teor de água, a massa fresca e seca da parte aérea do manjericão (BIONE et al.,
2014). O aumento da concentração salina da água de irrigação causou um efeito linear positivo sobre o teor de água na folha (Figura 3B). Esse aumento do teor de água na folha pode estar relacionado ao ajustamento osmótico. Segundo Taiz \& Zeiger (2008) o ajustamento osmótico é um processo pelo qual o potencial hídrico pode ser diminuído sem que haja decréscimo da turgescência ou do volume celular, pois com a manutenção da turgescência é possível a continuação do alongamento celular e uma condutância estomática mais alta sob potenciais hídricos mais baixos, sugerindo assim que o ajustamento osmótico seja um processo de aclimatação que aumenta a tolerância das plantas ao estresse salino.

Em alta concentração salina $\left(4,5 \mathrm{dS} \mathrm{m}^{-1}\right)$ as plantas de bananeira apresentaram alto teor de água na folha $(92,9 \%)$, indicando uma maior capacidade de absorção do solo, em condições de estresse osmótico, em compensar as perdas de água por transpiração foliar. Santana Júnior (2015) estudando a 
sensibilidade de cultivares de bananeira a níveis de salinidade, observou um efeito significativo da salinidade sobre as plantas com redução no Teor de água na folha, de maneira geral, à medida que aumentava a salinidade da água de irrigação. A Tabela 2 traz as médias dos tratamentos submetidos ao
Teste de Tukey a 5\%, na qual o fator tratamento $(\mathrm{T})$ foi significativo para as variáveis DP, NF, MSPA e TAF em que a água (controle negativo) e bactéria tiveram desempenho superior ao adubo para as variáveis diâmetro do pseudocaule (DP) e massa seca da parte aérea (MSPA).

Tabela 2. Teste de média para as variáveis diâmetro do pseudocaule (DP), número de folhas (NF) massa seca da parte área (MSPA) e teor de água na folha (TAF) de plantas de bananeira irrigadas com águas de diferentes concentrações salinas (CEa de 0,5, 1,5, 3,0, 4,5 $\mathrm{dS} \mathrm{m} \mathrm{m}^{-1}$ ).

\begin{tabular}{lcccc}
\hline & DP & NF & MSPA & TAF \\
\hline Água & $14,452 \mathrm{~A}$ & $5,438 \mathrm{~A}$ & $1,758 \mathrm{~A}$ & $88,509 \mathrm{~B}$ \\
Bactéria & $13,423 \mathrm{~A}$ & $4,625 \mathrm{~B}$ & $1,442 \mathrm{~A}$ & $90,007 \mathrm{~B}$ \\
Adubo & $11,177 \mathrm{~B}$ & $4,563 \mathrm{~B}$ & $0,769 \mathrm{~B}$ & $93,056 \mathrm{~A}$ \\
\hline
\end{tabular}

Médias seguidas de letras iguais na coluna não diferem estatisticamente entre si pelo teste de Tukey a 5\% de probabilidade.

Já para a variável número de folhas (NF) apenas o tratamento controle negativo (água) mostrou-se significativo. O teor de água na folha (TAF) teve seu efeito significativo apenas para o adubo, isto se deve ao fato de que a aplicação de adubo aumenta a quantidade de sais no solo elevando a necessidade da planta de promover ainda mais o ajustamento osmótico, aumentando mais o TAF.
A eficiência no uso da água (EUA) foi maior nas plantas irrigadas com concentrações salinas de 0,5 e $3,0 \mathrm{dS} \mathrm{m}^{-1}$, apresentando valores de, 0,70 e $0,58 \mathrm{~g}$ MSPA $/ \mathrm{m}^{2} / \mathrm{mm}$ respectivamente (Figura 4). As plantas que apresentam ajustamento osmótico, regulação estomática, relação fotossíntese/transpiração, por exemplo, são as mais eficientes no uso da água já que apresentam melhorias nas funções fisiológicas.

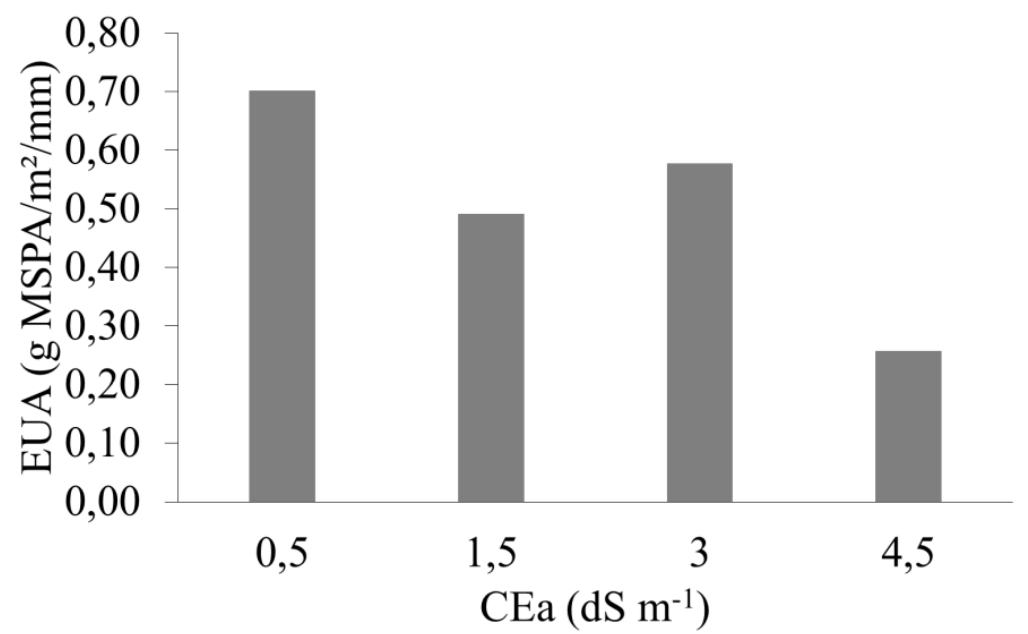

Figura 4. Eficiência do uso da água (EUA) de plantas de bananeira cv Prata Catarina, irrigadas com águas de diferentes concentrações salinas (CEa de 0,5, 1,5, 3,0, 4,5 dS m ${ }^{-1}$ ).

Em situações de estresse, como o salino, a planta tende a promover o ajustamento osmótico aumentando o teor de água na folha. Entretanto, a eficiência do uso da água tende a diminuir com o aumento da salinidade da água de irrigação, visto que é um a variável de caracterização que depende da quantidade de matéria seca da parte área da planta que com o aumento da salinidade tende a diminuir como mostrado na Figura 3A. 


\section{CONCLUSÕES}

A salinidade da água de irrigação afetou negativamente as variáveis $\mathrm{AP}, \mathrm{DP}, \mathrm{NF}, \mathrm{AF}$, MSPA e positivamente a TAF.

O tratamento com adubo apresentou resultado estatisticamente diferente dos demais tratamentos para as variáveis DP, TFA e MSPA.

O tratamento com bactéria apresentou resultado semelhante ao adubo, sendo estatisticamente diferente do tratamento com água (controle negativo) para a variável NF.

As bactérias não apresentaram influência direta nas respostas das mudas de bananeira ao estresse salino.

\section{REFERÊNCIAS BIBLIOGRÁFICAS}

AKBARI, M. M.; MOBASSER, H. R.; GANJALI, H. R. Influence of Salt Stress and Variety on some Characteristics of Corn. Biological Forum An L. International Journal, New Delhi, v. 7, n. 1, p. 441-445, 2015.

ARAÚJO FILHO, J. B.; GHEYI, H. R., AZEVEDO, N. C.; SANTOS, J. G. R. Efeitos da salinidade no crescimento e no teor de nutrientes em cultivares de bananeira. Revista Brasileira de Ciência do Solo, v. 19, p. 417422, 1995.

BIONE, M. A. A.; PAZ, V. P. S.; SILVA, F.; RIBAS, R. F.; SOARES, T. M. Crescimento e produção de manjericão em sistema hidropônico NFT sob salinidade. Revista Brasileira de Engenharia Agrícola e Ambiental, Campina Grande, v. 18, n. 12, p. 1228-1234, 2014. https://doi.org/10.1590/1807-

1929/agriambi.v18n12p1228-1234

CARMO, G. A.; MEDEIROS, J. F.; TAVARES, J. C.; GHEYI, H. R.; SOUZA, A. M.; PALÁCIO, E. A. Q. Crescimento de bananeiras sob diferentes níveis de salinidade da água de irrigação. Revista Brasileira de
Fruticultura, Jaboticabal, v. 25, n. 3, p. $513-$ 518, 2003. https://doi.org/10.1590/S010029452003000300038

CARVALHO, C. et al. Anuário brasileiro da fruticultura. Santa Cruz do Sul: Gazeta Santa Cruz, 2017.

COSTA, M. C. G.; MIOTTI, A. A.; FERREIRA, T. O.; ROMERO, R. E. Teor de nutrientes e viabilidade da bananicultura em Cambissolos com diferentes profundidades. Bragantia, v.75, n.3, p.335-343, 2016. https://doi.org/10.1590/1678-4499.359

FAO - Food and Agriculture Organization of The United Nations Statistics Division. 2019. Disponível em: <http://www. fao.org/faostat/en/\#data/QC>. Acesso em: 03 jan. 2019.

FERNANDES, M. R. V.; SILVA, T. A. C.; PFENNING, L. H.; COSTA-NETO, C. M.; HEINRICH, T. A.; ALENCAR, S. M.; LIMA, M. A.; IKEGAKI, M. Biological activities of the fermentation extract of the endophytic fungus Alternaria alternata isolated from Coffea arabica L. Brazilian Journal of Pharmaceutical Sciences, São Paulo, v. 45, n. 4, p. 677-685, 2009. https://doi.org/10.1590/S198482502009000400010

GOMES, E. W. F.; WILLADINO, L.; MARTINS, L. S. S.; SILVA, S. O.; CAMARA, T. R. Variedades de bananeira tratadas com água salinizada em fase inicial de crescimento. Revista Brasileira de Engenharia Agrícola e Ambiental, Campina Grande, v. 9, p. 31-36, 2005.

IBGE - Instituto Brasileiro de Geografia e Estatística. Sistema IBGE de recuperação automática - SIDRA. 2018. Disponível em: <https://sidra.ibge.gov.br/home/pmc/brasil>. Acesso em: 09 dez. 2018.

LACERDA, C. F.; SOUSA, G. G.; SILVA, F. L. B.; GUIMARÃES, F. V. A.; SILVA, G. L.; 
CAVALCANTE, L. F. Soil salinization and maize and cowpea yield in the crop rotation system using saline waters. Engenharia Agrícola, v. 31, n. 4, p. 663-675, 2011. https://doi.org/10.1590/S0100-

69162011000400005

LIMA, L.A.; OLIVEIRA, F.A. de; ALVES, R.C.; LINHARES, P.S.F.; MEDEIROS, A.M.A. de; BEZERRA, F.M.S. Tolerância da berinjela à salinidade da água de irrigação. RevistaAgro@mbiente On-line, Roraima, v. 9, n. 1, p. 27-34, jan. 2015. https://doi.org/10.18227/1982-

8470ragro.v9i1.2202

MUNNS, R.; TESTER, M. Mechanisms of salinity tolerance. Annual Review of Plant Biology, Palo Alto, v. 59, p. 651-681, 2008. https://doi.org/10.1146/annurev.arplant.59.032 607.092911

NEVES, L. L. M.; SIQUEIRA, D. L.; CECON, P. R.; MARTINEZ, C. A.; SALOMÃO, L. C. C. Crescimento, trocas gasosas e potencial osmótico da bananeira Prata, submetida a diferentes doses de sódio e cálcio em solução nutritiva. Revista Brasileira de Fruticultura, v. 24, p. 524-529, $2002 . \quad$ https://doi.org/10.1590/S010029452002000200049

OLIVEIRA, F. A.; OLIVEIRA, F. R. A.; CAMPOS, M. S.; OLIVEIRA, M. K. T.; MEDEIROS, J. F.; SILVA, O. M. P. Interação entre salinidade e fontes de nitrogênio no desenvolvimento inicial da cultura do girassol. Revista Brasileira de Ciências Agrárias, Pernambuco, v. 5, n. 4, p. 479-484, 2010. https://doi.org/10.5039/agraria.v5i4a806

PEREIRA JUNIOR, J. S. Nova delimitação do semiárido brasileiro. Brasília, DF: Centro de Documentação e Informação, 2007.

PRAZERES, S.S.; LACERDA, C.F.; BARBOSA, E.L.B.; AMORIM, A.V.; ARAUJO, I.C.S.; CAVALCANTE, L. F.
Crescimento e trocas gasosas de plantas de feijão-caupi sob irrigação salina e doses de potássio. Revista agro@mbiente On-line, v. 9, n. 2, p. 111-118, 2015. https://doi.org/10.18227/1982-

8470ragro.v9i2.2161

SÁ, F. V. DA S.; BRITO, DE MELO, M. E. B.; A. S.; NETO, P. A.; FERNANDES, P. D.; FERREIRA, I. B. Produção de mudas de mamoeiro irrigadas com água salina. Revista Brasileira de Engenharia Agrícola e Ambiental, v.17, n. 10, p. 1047-1054, 2013. https://doi.org/10.1590/S141543662013001000004

SALOMAO, L. C. C.; SIQUEIRA, D.L.; LINS, L. C. R.; CECON, P. R. Crescimento e produção da bananeira (Musa spp. AAB) 'Prata-Anã', oriunda de rizoma e micropropagada. Revista Ceres, v. 63, n. 3, p. 340-347, 2016. https://doi.org/10.1590/0034737X201663030010

SANTANA JÚNIOR, E. B. Sensibilidade de cultivares de bananeira a níveis de salinidade na água de irrigação. 2015. 136 f. Tese (Doutorado em Ciências Agrárias) Universidade Federal do Recôncavo da Bahia, Cruz das Almas.

SILVA, R. L. O.; MARTINS, L. S. S.; GOMES, E. W. F.; FERRAZ, G. M. G.; SILVA, S. O.; VIEIRA, L. M. Síntese Anual da Agricultura de Santa Catarina 2012-2013. Banana. Epagri/Cepa, Florianópolis, SC, p. 18-25, 2013.

TAIZ, L.; ZEIGER, E. Fisiologia vegetal. 4. ed. Porto Alegre: Artmed, 719 p. 2008.

WILLADINO, L. Avaliação de diploides de bananeira (Musa spp.) quanto à tolerância a salinidade. Revista Brasileira de Fruticultura. v. 31, p. 1084-1091, 2009. https://doi.org/10.1590/S0100-

29452009000400023 